\title{
Solving the Multi Objective Programming Problem Using Mean and Median Value
}

\author{
Najmaddin A. Sulaiman \\ College of Education
}

\author{
Gulnar, W. Sadiq \\ College of science
}

University of Salahaddin

Received on: 25/04/2005

Accepted on: 04/09/2005

\begin{abstract}
In this paper, the present algorithm [4] to solve fractional programming problem for multi objective functions, investigate the algorithm to solve linear programming problem for multiobjective functions [2], the computer application of algorithm was tested on a number of numerical examples and modify the approach by using mean and median for values of objective functions, to combine objective function from objective functions for linear programming problem for multi objective functions then it has been improved the above algorithm to solve the problem and computer application of improvement algorithm has been demonstrated by a flow chart and solving numerical examples on the computer then the good results have been often, as compared to the previous method [2].
\end{abstract}

Keywords: fractional programming problem, Multiobjctive linear programming problem.

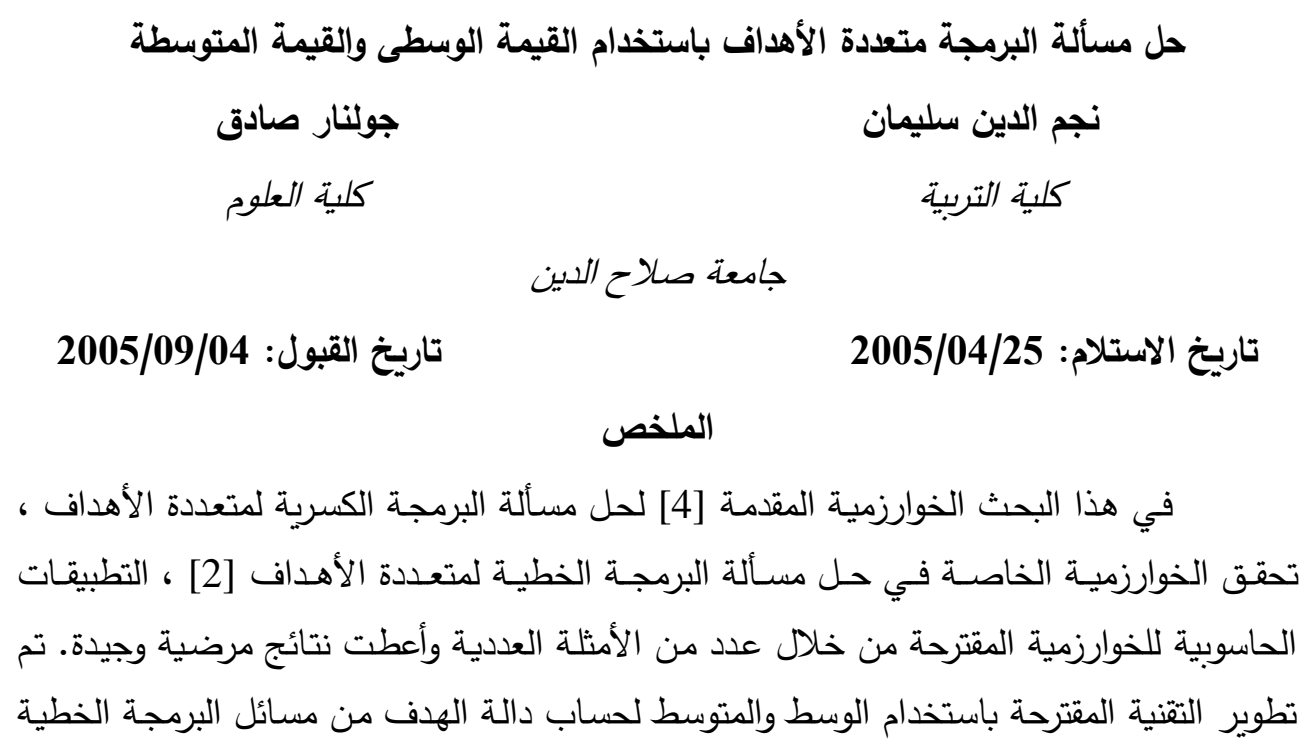




$$
\begin{aligned}
& \text { لمتعددة الأهداف، وتم تحسين الخوارزمية العليا لها من خلال الاختبارات التطبيقية وكانت النتائج }
\end{aligned}
$$

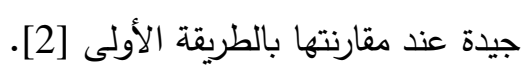

$$
\begin{aligned}
& \text { الكلمات الرئيسية: البرمجة الكسرية، البرمجة الخطية متعددة الاهداف. }
\end{aligned}
$$

\section{Introduction:}

In (1983), Chandra Sen[2] defined the multiobjective linear programming problem and suggested an approach to construct the multi objective function under the limitation that the optimum value of individual problem is greater than zero, but he has not considered the situation when the optimum value of some of the individual objective functions may be negative or zero also.

In (1989), Sulaiman [3] studied the computational aspects of single objective indefinite Q-programming problem. In (1993), Abdil-Kadir and Sulaiman [4] studied the multiobjective fractional programming problem.

In order to extend this work we have defined a multiobjective linear programming problem and investigated the algorithm to solve linear programming problem for multiobjective functions [2].

Irrespective of the number of objectives with less computational burden and suggest a new technique by using mean and median value of objective functions, to generate the best optimal solution. The computer application of our algorithm has also been discussed by solving a numerical examples.

\section{2.mathematical form of the multiobjective programming problem :}

The multiobjective programming problem is defined as follows:

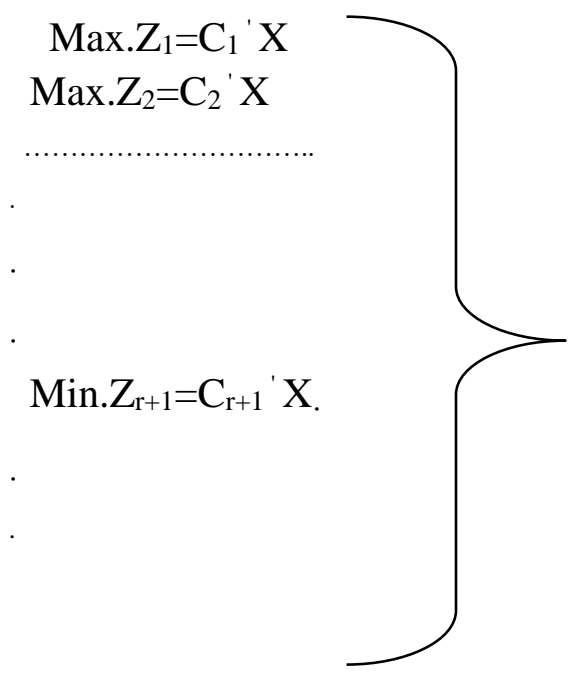


Min. $\mathrm{Z}_{\mathrm{s}}=\mathrm{C}_{\mathrm{s}}{ }^{\prime} \mathrm{X}$

Subject to

$$
\begin{aligned}
& \text { A.X }=\text { B..... (2) } \\
& X \geq 0 \ldots \ldots . .(3)
\end{aligned}
$$

Where $X$ is an $n$-dimensional vector of decision variables, $r$ is the number of objective functions that is to be maximized, (s-r ) is the number of objective functions that is to be minimized, and $C_{i}(i=1,2, \ldots, s)$ are $n$ dimensional vector of constants. In addition, $\mathrm{B}$ is $\mathrm{m}$-dimensional vector of constants, $\mathrm{A}$ is a (mxn) matrix of coefficients.

All vectors are assumed to be column vectors unless transposed, (' ). $[1,2]$

\section{Definition (1):}

Mean: the point of balance or average of a data set

$$
\begin{aligned}
& \text { arithmetic mean }=\frac{\sum_{i=1}^{n} y_{i}}{n} \\
& \text { sample mean }=\overline{\mathrm{y}} \\
& \text { population mean }=\mu
\end{aligned}
$$

\section{Definition (2):}

Median: the mid-point of a data set when the data set of observations is placed in an ascending order - (Note: the median does not have to be a point in the data set)

sample median $=\mathrm{m}$

population median $=\tau$

For an odd number of observations the median is the data point which falls in the middle, at location $X(n+1) / 2$ when values are placed in an ascending order.

For an even number of observations, the median is defined by the mean of the 2 middle observations at locations: $X(n / 2), X(n / 2)+1$ Thus, median is the value represented by the average of the points at locations $X$ $(\mathrm{n} / 2), \mathrm{X}(\mathrm{n} / 2)+1$. [7] 


\section{Formulation of multi objective functions:}

The same approach taken by Kadr and Sulaiman[4] for multiobjective fractional function is followed here to formulate the constrained objective functions given in equation(1).

Suppose we obtained a single value corresponding to each of the objective functions of it being optimized individually subject to the constraints (2)and(3) as follows:

$\operatorname{Max} . Z_{1}=\varphi_{1}$

$\operatorname{Max} . Z_{2}=\varphi_{2}$

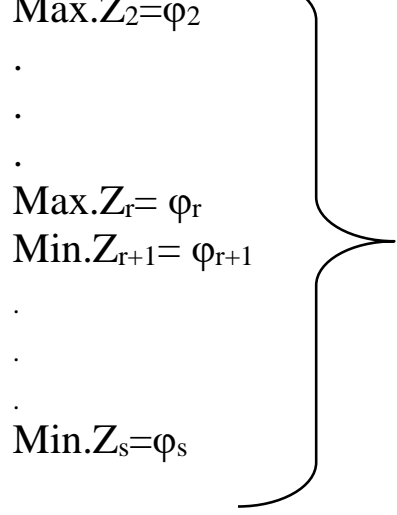

Where $\varphi_{1}, \varphi_{2}, \ldots, \varphi_{\mathrm{r}}, \varphi_{\mathrm{r}+1, \ldots}, \varphi_{\mathrm{s}}$ the decision variable may not necessarily be common to all optimal solutions in the presence of conflicts among objectives.

But we require the common set of decision variable to be the best compromising optimal solution [8]

Hence, we can determine the common set of decision variables from the following combined objective function (see Chandra Sen[2], 1983)

Which formulate the MOLPP given in (1)

$\operatorname{Max} . Z=\sum_{k=1}^{r} \frac{Z_{k}}{\left|\varphi_{k}\right|}-\sum_{k=r+1}^{s} \frac{Z_{k}}{\left|\varphi_{k}\right|} \ldots \ldots .$.

Where $\varphi_{\mathrm{k}} \neq 0,(\mathrm{k}=1,2, \ldots, \mathrm{s})$

Subject to the same constraints (2), (3), and the optimum value of the

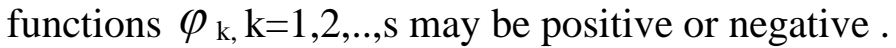

\section{ALGORITHM (1):}


The following algorithm is to obtain the optimal solution for the multiobjective linear programming problem defined in previous can be summarized as follows:-

STEP 1: Find the value of each of individual objective functions which is to be maximized or minimized

STEP2: Solve the first objective problem by the simplex method.

Step 3: check the feasibility of the solution obtained in step 2 if it is feasible then go to step 4, otherwise, use dual simplex methods to remove infeasibility.

STEP4: Assign a name to the optimum value of the first objective function $Z_{1}$.say $\varphi_{1}$ then calculate $\frac{Z_{1}}{\left|\varphi_{1}\right|}$

STEP 5: Repeat the steps 2 and 3 to obtain $\frac{Z_{i}}{\left|\varphi i_{i}\right|}$, for $\mathrm{i}=1,2, \ldots, \mathrm{r}, \mathrm{r}+1, \ldots, \mathrm{s}$

STEP 6: Construct the combined objective function, which has the formula (5)

STEP 7: Optimize the combined objective function under the same constraints (2) and (3) by repeating the steps 2 to 4

Program Notations:

The following notations, which are used in computer program, are defined as follows: -

$\varphi A=$ the value of objective function which is to be maximized

$\varphi L=$ the value of objective function which is to be minimized
$\mathrm{AA}=|\varphi A|$
$\mathrm{AL}=|\varphi L|$
$\mathrm{DG}=\frac{Z}{A A}$
$\mathrm{SG}=\sum_{i \approx 1}^{r} D G i$
$\mathrm{DL}=\frac{Z}{A L}$
$\mathrm{SL}=\sum_{i=r+1}^{s} D L i$
$\mathrm{Z}=\mathrm{SG}-\mathrm{SL}$

Numerical Examples: 
Example (1):

$\operatorname{Max} . Z_{1}=X_{1}$

$\operatorname{Max} \cdot Z_{2}=X_{1}+X_{2}$

Subject to

$$
\begin{gathered}
5 X_{1}+2 X_{2} \leq 22 \\
X_{2} \leq 6 \\
X_{1}, X_{2} \geq 0
\end{gathered}
$$

\section{Solution:}

Max. $Z_{1}=4.4$

$\Phi \mathrm{A}_{1}=4.4$

$\mathrm{AA}_{1}=4.4$

$\mathrm{DG} 1=\frac{Z 1}{A A 1} \approx \frac{X 1}{4.4}$

$\mathrm{SG} 1=0.2273 \mathrm{X}_{1}$

2. $\operatorname{Max} . Z_{2}=8$

$\Phi \mathrm{A}_{2}=8$

$\mathrm{AA}_{2}=8$

$\mathrm{DG} 2=\frac{Z 2}{A A 2} \approx \frac{X 1+X 2}{8}$

$\mathrm{SD} 2=0.125 \mathrm{X}_{1}+0.125 \mathrm{X}_{2}$

$\therefore M A X . Z \approx S G 1+S G 2$

$$
\begin{aligned}
& \approx 0.2273 X 1+0.125 X 1+0.125 X 2 \\
& \approx 0.3523 X 1+0.125 X 2
\end{aligned}
$$

$\therefore$ Our objective function is:

$$
\text { Max. } Z=0.3523 \mathrm{X}_{1}+0.125 \mathrm{X}_{2}
$$

Subject to the given constraints

$$
\begin{aligned}
& 5 X_{1}+2 X_{2} \leq 22 \\
& X_{2} \leq 6 \\
& X_{1}, X_{2} \geq 0
\end{aligned}
$$

After solving $\mathrm{Z}$ by simplex method we get that

$$
\text { Max .Z=1.5501 }
$$

$\mathrm{X}_{1=4.4}$

$\mathrm{X}_{2=0}$

\section{Example (2):}


Solve the following multiobjective linear p.p. by Chandra Sen method

and

Max. $Z_{1}=3 X_{1}+2 X_{2}$

$\operatorname{Max} . Z_{2}=4 X_{1}+X_{2}$

Max. $Z_{3}=4 X_{1}-2 X_{2}$

Max. $Z_{4}=15 X_{1}+4 X_{2}$

Min. $Z_{5}=-6 X_{1}+2 X_{2}$

Min. $Z_{6}=-9 X_{1}+3 X_{2}$

Min. $Z_{7}=-5 X_{1}+2 X_{2}$

Subject to:

Solution: -

$$
\begin{aligned}
& \mathrm{X}_{1}+\mathrm{X}_{2} \leq 4 \\
& \mathrm{X}_{1}-\mathrm{X}_{2} \leq 2 \\
& \mathrm{X}_{1}, \mathrm{X}_{2} \geq 0
\end{aligned}
$$

First we solve each objective function w.r.to the given constraints individually by the Simplex method we get:
$\mathrm{Z}_{1}=11, \mathrm{X}_{1}=3, \mathrm{X}_{2}=1$
and
$\mathrm{AA}_{1}=11$
$Z_{2}=13, X_{1}=3, X_{2}=1$
$\mathrm{AA}_{2}=13$
$Z_{3}=10, X_{1}=3, X_{2}=1$
$\mathrm{AA}_{3}=10$
$\mathrm{Z}_{4}=49, \mathrm{X}_{1}=3, \mathrm{X}_{2}=1$
$\mathrm{AA}_{4}=49$
$Z_{5}=-16, X_{1}=3, X_{2}=1$
$\mathrm{AL}_{5}=16$
$Z_{6}=-24, X_{1}=3, X_{2}=1$
$\mathrm{AL}_{6}=24$
$Z_{7}=-13, X_{1}=3, X_{2}=1$
$\mathrm{AL}_{7}=13$
$\mathrm{DG}_{1}=\mathrm{Z}_{1} / 11=0.27 \mathrm{X}_{1}+0.18 \mathrm{X}_{2}$
$\mathrm{DG}_{2}=\mathrm{Z}_{2} / 13=0.31 \mathrm{X}_{1}+0.08 \mathrm{X}_{2}$
$\mathrm{DG}_{3}=\mathrm{Z}_{3} / 10=0.4 \mathrm{X}_{1}-0.2 \mathrm{X}_{2}$
$\mathrm{DG}_{4}=\mathrm{Z}_{4} / 49=0.31 \mathrm{X}_{1}+0.08 \mathrm{X}_{2}$
$\mathrm{SG}=\sum_{i \approx 1}^{4} D G i=1.29 \mathrm{X}_{1}+0.14 \mathrm{X}_{2}$
$\mathrm{DL}_{5}=\mathrm{Z}_{5} / 16=-0.38 \mathrm{X}_{1}+0.13 \mathrm{X}_{2}$
$\mathrm{DL}_{6}=\mathrm{Z}_{6} / 24=-0.38 \mathrm{X}_{1}+0.13 \mathrm{X}_{2}$
$\mathrm{DL} 7=\mathrm{Z}_{7} / 11=-0.38 \mathrm{X}_{1}+0.15 \mathrm{X}_{2}$
$\mathrm{SL}=\sum_{i \approx 5}^{7} D L i=-01.14 \mathrm{X} 1+0.41 \mathrm{X}_{2}$
$\mathrm{Z}=\mathrm{SG}-\mathrm{SL}=2.43 \mathrm{X}_{1}+0.27 \mathrm{X}_{2}$ 
$\therefore \quad$ Max.Z $=2.43 \mathrm{X}_{1}-0.27 \mathrm{X}_{2}$

Subject to:

$$
\begin{aligned}
& \mathrm{X}_{1}+\mathrm{X}_{2} \leq 4 \\
& \mathrm{X}_{1}-\mathrm{X}_{2} \leq 2 \\
& \mathrm{X}_{1}, \mathrm{X}_{2} \geq 0
\end{aligned}
$$

Solve by simplex method we get:

$$
\begin{aligned}
& \text { Max.Z }=7.02 \\
& X_{1}=3 \\
& X_{2}=1
\end{aligned}
$$

\section{4.improved approach using mean and median value:}

We formulate the combined objective function as follows to determine the common set of decision variables

$\operatorname{Max} . Z=\frac{\sum_{i \approx 1}^{r} Z i}{\operatorname{Mean}(A A i)}-\frac{\sum_{i \approx r+1}^{s} Z i}{\operatorname{Mean}(A L i)}$

$\operatorname{Max} . Z=\frac{\sum_{i \approx 1}^{r} Z i}{\operatorname{Median}(A A i)}-\frac{\sum_{i \approx r+1}^{s} Z i}{\operatorname{Median}(A L i)} \ldots \ldots$

All other approaches and symbols in section 3 are the same to be applied in this section

\section{ALGORITHM (2):}

STEP 1, STEP2: the same as before.

STEP 3: Also the same as before

STEP4: Assign a name to the optimum value of the objective function $\mathrm{Z}_{\mathrm{I}}$. say $\varphi_{\mathrm{i}}(\mathrm{i}=1,2, \ldots, \mathrm{s})$.

STEP 5: find the mean, median of $\varphi_{i}, \mathrm{i}=1, \ldots, \mathrm{s}$., calculate $\mathrm{Zi} /$ mean \& $\mathrm{Zi} /$ mediam .

STEP 6: Construct the combined objective function which has the formula(6) or (7).

STEP 7: Optimize the combined objective function under the same constraints (2)and( 3 ) .

\section{PROGRAM NOTATION:}


AA and AL have the same meaning as before with these new

notations

$\mathrm{VM}=\operatorname{Mean}\left(\mathrm{AA}_{\mathrm{i}}\right)$ or median $\left(\mathrm{AA}_{\mathrm{i}}\right),(\mathrm{i}=1,2, \ldots, \mathrm{r})$.

$\mathrm{VN}=\operatorname{Mean}\left(\mathrm{AA}_{\mathrm{i}}\right)$ or Median $\left(\mathrm{AA}_{\mathrm{i}}\right),(\mathrm{i}=\mathrm{r}+1, \ldots, \mathrm{s})$.

$\mathrm{SM}=\sum_{i \approx 1}^{r} Z i$

$\mathrm{SN}=\sum_{i \approx r+1}^{s} Z i$

$\mathrm{S}_{1}=\frac{S M}{V M}$

$\mathrm{S}_{2}=\frac{S N}{V N}$

$\mathrm{Z}=\mathrm{S}_{1}-\mathrm{S}_{2}$

NUMMRICAL EXAMPLES:

Example (1):

If we consider example (1) before

$\operatorname{Max} \cdot Z_{1}=X_{1}$

$\operatorname{Max} . Z_{2}=X_{1}+X_{2}$

Subject to :

$$
\begin{gathered}
5 \mathrm{X}_{1}+2 \mathrm{X}_{2} \leq 22 \\
\mathrm{X}_{2} \leq 6 \\
\mathrm{X}_{1}+\mathrm{X}_{2} \geq 0
\end{gathered}
$$

\section{Solution:-}

$\operatorname{Max} . Z_{1}=4.4$

$\operatorname{Max} . Z_{2}=8$

$\varphi A 1 \approx 4.4$

$\mathrm{AA}_{1} \approx 4.4$

$\varphi A 2 \approx 8$

$\mathrm{AA}_{2}=8$

$\mathrm{VM} \approx 6.2$

$$
\mathrm{VD}_{1} \approx \frac{X 1}{6.2}
$$

$\mathrm{VD}_{2} \approx \frac{X 1+X 2}{6.2}$

$\mathrm{Z}_{\mathrm{opt} .}=0.1612 \mathrm{X}_{1}+0.1612 \mathrm{X}_{1}+0.1612 \mathrm{X}_{2}$ 
$=0.3224 X_{1}+0.1612 X_{2}$

$\therefore \quad$ Our objective function is:

$\max . Z \approx 0.3224 X_{1}+0.1612 X_{2}$

Subject to

$$
\begin{gathered}
5 X_{1}+2 X_{2} \leq 22 \\
X_{2} \leq 6 \\
X_{1}, X_{2} \geq 0
\end{gathered}
$$

\section{SOLUTIN:}

Max.Z1 $\approx 1.6120$

$\mathrm{X}_{1} \approx 2$

$\mathrm{X}_{2} \approx 6$

\section{Example (2):}

(b)modified Chandra Sen method:

$\mathrm{VM}=\frac{\sum_{i \approx 1}^{4} A A i}{4}=\frac{11+13+10+49}{4} \approx 20.75$

$\mathrm{SM}=\sum_{i \approx 1}^{4} Z i=26 X 1+5 X 2$

$\mathrm{S}_{1}=\frac{S M}{V M} \approx 1.25 X 1+0.24 X 2$

$\mathrm{VN}=\frac{\sum_{i \approx 5}^{7} A L i}{3} \approx 17.67$

$\mathrm{SN}=-20 \mathrm{X}_{1}+7 \mathrm{X}_{2}$

$\mathrm{S}_{2}=\frac{S N}{V N} \approx-1.13 X 1-0.40 X 2$

$\mathrm{Z}=\mathrm{S}_{1}+\mathrm{S}_{2}$

$=2.38 \mathrm{X}_{1}-0.16 \mathrm{X}_{2}$

$\therefore$ Max.Z $=2.38 \mathrm{X}_{1}-0.16 \mathrm{X}_{2}$ 
Subject to:

$$
\begin{aligned}
& X_{1}+X_{2} \leq 4 \\
& X_{1}-X_{2} \leq 2 \\
& X_{1}, X_{2} \geq 0
\end{aligned}
$$

Solve $\mathrm{Z}$ by simplex method we get:

Max.Z=6.98

$\mathrm{X}_{1}=3, \mathrm{X}_{2}=1$

NOTE:

Since we have an outlier $\mathrm{AA}_{\mathrm{i}}$,hence we use $\overline{M e}$ in place of $\mathrm{AV}$.

$$
\begin{aligned}
& \mathrm{VM}=\overline{M e}=\frac{X \frac{4}{2}+X \frac{4}{2}+1}{2}=\frac{X 2+X 3}{2}=\frac{11+13}{2}=\frac{24}{2}=12 \\
& \therefore \quad \overline{M e}=12 \\
& \therefore \quad \mathrm{VM}=12 \\
& \mathrm{SM}=26 \mathrm{X}_{1}+5 \mathrm{X}_{2} \\
& \mathrm{~S}_{1}=\frac{S M}{V M} \approx 2.17 X 2+0.42 X 2 \\
& \mathrm{~S}_{2}=-1.13 \mathrm{X}_{1}+0.40 \mathrm{X}_{2} \\
& \therefore \quad \quad \mathrm{Z}=\mathrm{S}_{1}-\mathrm{S}_{2} \\
& \quad=3.3 \mathrm{X}_{1}+0.02 \mathrm{X}_{2}
\end{aligned}
$$

$\therefore \quad$ Max.Z1 $=3.3 \mathrm{X}_{1}+0.02 \mathrm{X}_{2}$

Subject to:

$$
\begin{aligned}
& X_{1}+X_{2} \leq 4 \\
& X_{1}-X_{2} \leq 2 \\
& X_{1}, X_{2} \geq 0
\end{aligned}
$$

Solving $\mathrm{Z}$ by simplex method we get:

Max.Z1=9.92

$\mathrm{X}_{1}=3$

$\mathrm{X}_{2}=1$ 
Flow-chart (1):

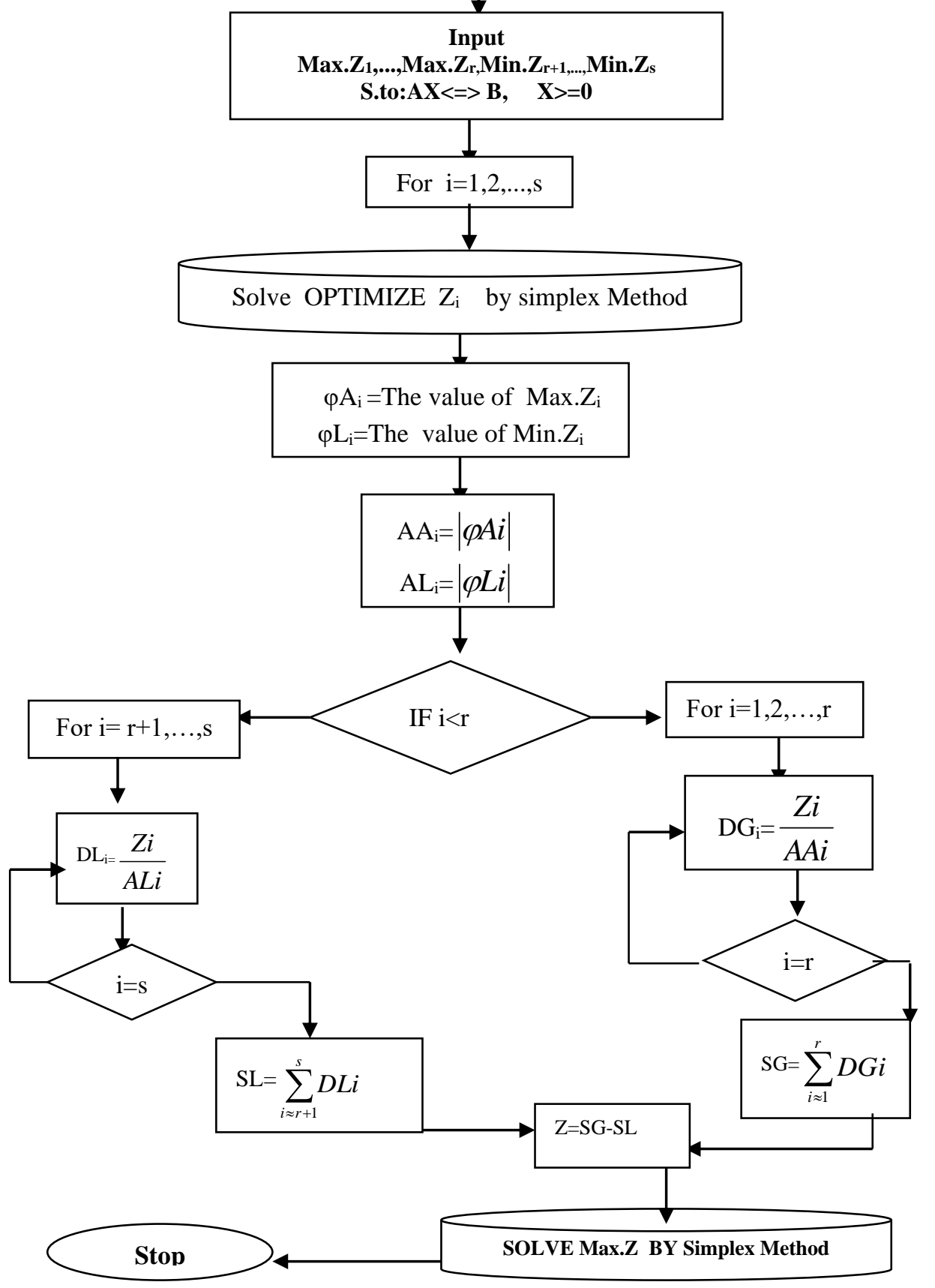


Flow-chart (2):

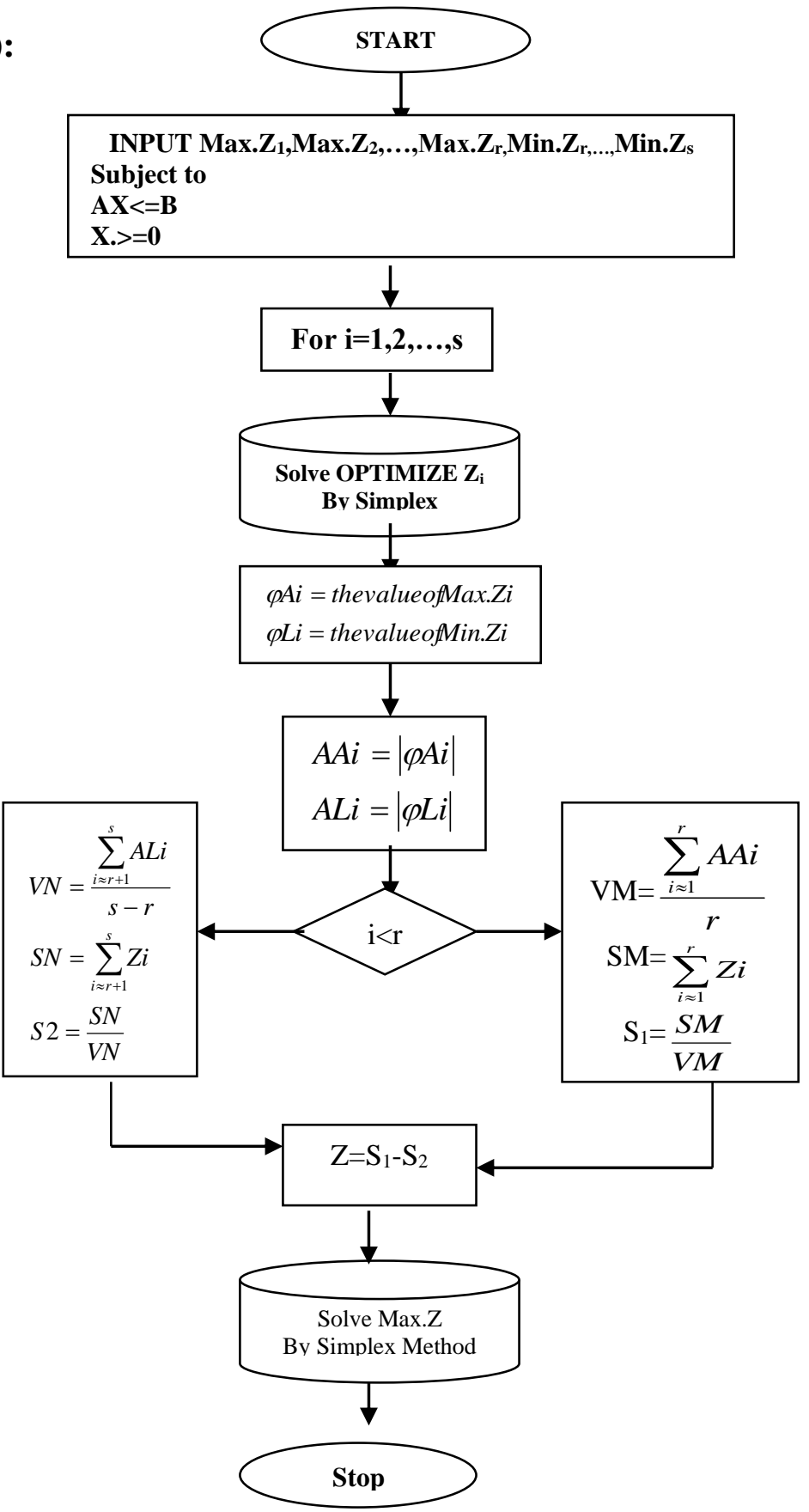


Table (1): Results of two approachs :-

\begin{tabular}{|l|l|l|l|}
\hline Example & Chandra Sen approach & \multicolumn{2}{l|}{ Modified approach } \\
& & & \\
\hline & & Using mean & Using median \\
\hline & & $Z_{\text {opt. }}=1.61220$ & $Z_{\text {opt. }}=1.61220$ \\
& $\mathrm{Z}_{\text {opt. }}=1.5501$ & $\mathrm{X}_{1}=2$ & $\mathrm{X}_{1}=2$ \\
& $\mathrm{X}_{1}=4.4$ & $\mathrm{X}_{2}=6$ & $\mathrm{X}_{2}=6$ \\
\hline Example (1) & $\mathrm{X}_{2}=0$ & $\mathrm{Z}_{\text {opt. }}=6.98$ & $\mathrm{Z}_{\text {opt. }}=9.92$ \\
& $\mathrm{Z}_{\text {opt. }}=7.02$ & $\mathrm{X}_{1}=3$ & $\mathrm{X}_{1}=3$ \\
& $\mathrm{X}_{1}=3$ & $\mathrm{X}_{2}=1$ & $\mathrm{X}_{2}=1$ \\
\hline & $\mathrm{X}_{2}=1$ & & \\
\hline
\end{tabular}

\section{Conclusion:}

Chandra Sen approach takes a lot of time than our modification. It is clear from their flow-charts, since Chandra Sen approache compute $\frac{Z_{i}}{\left|\varphi_{i}\right|}$ for each $\mathrm{i}(\mathrm{i}=1,2, \ldots, \mathrm{s})$ which takes a lot of time when the number of objective functions is greater.

In our modification the median is better than the mean when there is an outlier in the value of objective functions.

when there is only two objective functions one is to be maximized and the other is minimized then the result is the same for both Chandra Sen and our modification

For both cases the introduced objective function, Z, is to be maximized. 


\section{REFERENCES}

[1] Artem, V.B.;Dragan, A. S. and Goldfrey, A.W.(2004) Multiobjective optimization of water.

[2] Sen Chandra (1983) "A new approach for multiobjective rural development planning" The Indian Economic Journal Vol.30, No.4, $\mathrm{pp}(91-96)$.

[3] Sulaiman, A.N.(1989) "Extreme point Quadratic programming technique, M.Sc.Thesis", University of Salahaddin.

[4] Abdil-Kadir ,M.S. and Sulaiman, N.A.(1993) "An approach for multiobjective fractional programming problem" Journal of the College of Education, Univ. Salahaddin, Vol.3, No.1, pp(1-5).

[5] Bunday,B.D.(1984) "Basic Linear programming" Edward Arnold, $\mathrm{p}(163)$.

[6] Bunday, B.D. and Garside,G.R. (1987) "Linear programming in pascal" Edward Arnold, p(188).

[7] Jack Levin and James Alan Fox (2003), Northeastern University "Elementary Statistics in Social Research" $9^{\text {th }}$ ed. www.ablongman.com/levinstats9e

[8] Ward Cheney and David Kincaid (2004) "Numerical Mathematics and computing "fifth edition, Thomson. 